\title{
Gunnar af Björkesten (1912-1974)—pioneer of Finnish neurosurgery: the surgeon and the man
}

\author{
Rossana Romani • Henry Troupp
}

Received: 27 February 2014 / Accepted: 7 March 2014 / Published online: 3 April 2014

(C) Springer-Verlag Wien 2014

In much of the twentieth century neurosurgery was a heroic specialty, not least for the patients. Through the efforts of many charismatic figures the specialty gradually established itself. One such pioneer of neurosurgery was Gunnar af Björkesten, born in Helsinki in 1912. He brought modern neurosurgery to Finland in 1952, and headed the Helsinki department from 1962 to 1973. Professor Henry Troupp, his successor and head of the department until 1990, described him in an obituary:

"In many ways - as a pioneer in his field, as a fine neurosurgeon, as a brave and intelligent administrator, he was one of Finland's great men, though the faithful professional men are not usually the sung heroes in a country's annals. Yet what is more, he was truly a good man" [4].

\section{Twentieth century: World War II and neurosurgery in Finland}

A dedicated neurosurgical service was started in Finland by Aarno Snellman (1893-1964), a general surgeon who worked at the beginning of his career with Simo A. Brofeldt (18921942), the head of the Red Cross Hospital (today Töölö Hospital). In the spring of 1935, Brofeldt sent Snellman to Herbert Olivecrona at the Serafimer Hospital Stockholm for 6

\footnotetext{
R. Romani $(\bowtie)$

University of Helsinki, Terveystalo, Jaakonkatu 3, 4 krs,

Helsinki 00100, Finland

e-mail: rossana.romani@helsinki.fi

H. Troupp

University of Helsinki, Helsinki, Finland

e-mail: heutropp@bastu.net
}

months. When Snellman returned to Finland, he performed his first neurosurgical operation on 18 September 1935 [1].

Other surgeons before him had tried their hand at neurosurgery: Ali Krogius, Richard Faltin, and A.J. Palmén and Väinö Seiro. The Ph.D. thesis of Palmén in 1914 was entitled "Features of Intervertebral Tumour". Another person contributing to the field of neurosurgery in Finland was Fabian Langenskiöld, who had been a student of Cushing in 1929. The Red Cross Hospital was Finland's only centre for neurosurgery until 1967 [2, 3].

\section{Gunnar af Björkesten}

Gunnar af Björkesten (1912-1974) was born in Helsinki, graduated in 1938, and became a specialist in general surgery in 1945. The years of the Second World War were crucial in his professional life: he came into close contact with Swedish and Danish neurosurgeons who had come to Finland to help in handling brain injuries.

He wrote and published his Ph.D. thesis on the results of treatment of war injuries to peripheral nerves, covering 1,400 cases that he had mainly operated on himself.

With the help of Professor Aarno Snellman, soon after the war he got the chance to move to Stockholm, first to work with Olof Sjöqvist at Södersjukhuset for 4 years, 1947-1952, and later, for a few months, with Herbert Olivecrona. This Swedish experience was a milestone in his life, for the outstanding quality of Swedish neurosurgery and neuroradiology at the time, and for further international contacts he was able to make (Fig. 1).

In the summer of 1952 he came back to Finland, still recovering from the after-effects of the war. At that time the neurosurgical department had 20 beds, considered enough for the needs of 4.1 million people. Gunnar af Björkesten refused to be discouraged, and started up aneurysm surgery. This 


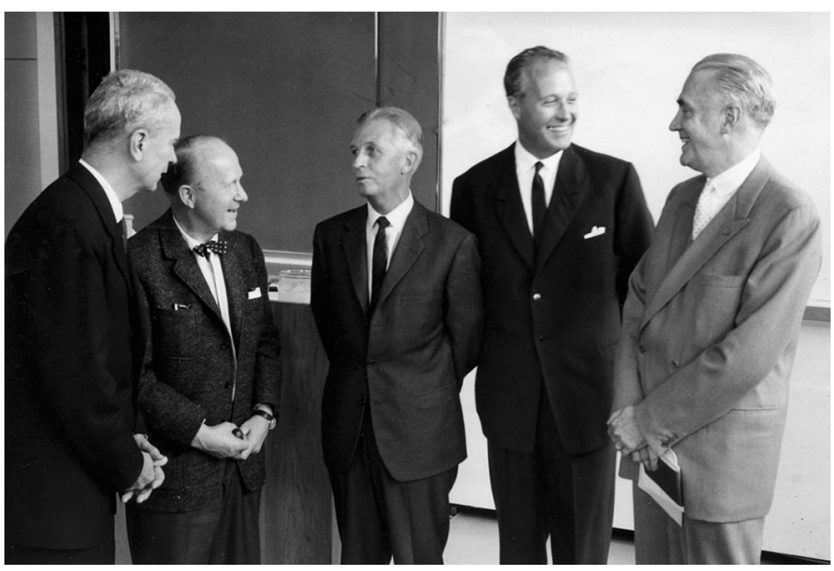

Fig. 1 Gunnar af Björkesten in international neurosurgical company, left to right: Aron Petter Lindström (US), Bendt Broager (DK), Kristian Kristiansen (N), Gunnar af Björkesten, Lars Leksell (S) (Private collection of Professor Gunnel Adlercreutz, née af Björkesten, copyright: gunnel@adlercreutz.fi)

subject fascinated af Björkesten for the rest of his life: his last paper was on the timing of aneurysm operations.

In the mid-1950s af Björkesten applied for a 3-month Asla scholarship to the US. Finland at the time was still paying off a debt of the 1920s to the US, who rewarded the country for its punctiliousness by giving Finland back the same amount in the form of scholarships. Besides his native Swedish and Finnish, he also had good German, some French and in the US he honed his English.

Contacts, travels and experience made af Björkesten an open-minded and progressive neurosurgeon. During the 1960s he started a randomised clinical trial over 5 years to find out whether the aneurysm surgery at the Helsinki Department of Neurosurgery had really been worth doing. The trial proved that only an earlier operation, within the first 3 weeks after bleeding, would justify operation over conservative treatment. In the 1960s a retrospective analysis had shown that the department's results with acoustic neurinomas were poor. He took them on and improved the results as long as he was head. In the operating theatre he was calm and controlled. The only thing that could sometimes arouse his wrath was if anyone showed callousness towards a patient.

From Sweden, he brought the tradition of a personal early reply to every doctor referring a patient to the department; this was not common in the Finland of the 1950s and 1960s.

For many years the staff of the department were invited to spend a day on the island (Tostholm) of the Björkesten summer place on the Gulf of Finland: walking on the island, swimming, fishing, lunching and frequently water skiing (Fig. 2). Usually 15-20 members of staff could be spared from the routine running of the department, plus any foreign visitors around.

Gunnar af Björkesten was a founding member of the Scandinavian Neurosurgical Society, a corresponding member of the Deutsche Gesellschaft für Neurochirurgie and the

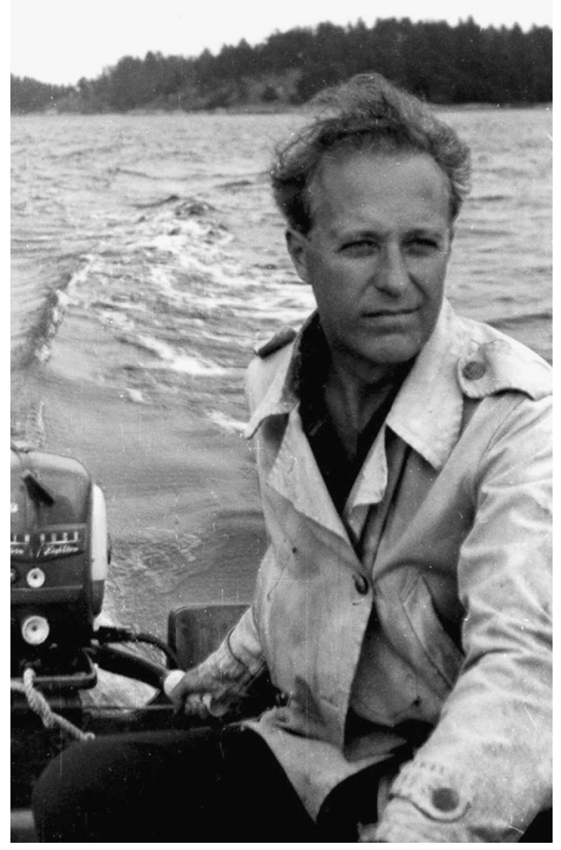

Fig. 2 Gunnar af Björkesten at his much loved summer place, Tostholm, southern coast of Finland, 14 August 1960. (Private collection of Professor Gunnel Adlercreutz, née af Björkesten, copyright: gunnel@adlercreutz.fi)

American Association of Neurological Surgeons. He had friends all over the world. His close friends also saw this gentle and soft-spoken man in his family circle.

Throughout his life af Björkesten enjoyed watching games, soccer, ice hockey, tennis; he also enjoyed watching field athletics at the Olympic Stadium in Helsinki. He was a high jumper on the Finnish national youth team in the 1930s, and played tennis into his late 50s. In his later years he also took to golf.

Gunnar af Björkesten came from a family of mathematicians on his mother's side and good musicians on both sides. He sang in a men's choir in his youth and played the piano, sometimes four-handed with his wife. He enjoyed classical music and is remembered by friends as occasionally "conducting" the music off the record player.

He was known for his good manners and his good nature. The last operation he did, on 12 March 1973, was an acoustic neurinoma. When he downed tools and walked out of the theatre no-one but himself would have known that it was his last operation. Very few people outside the family had noticed that he had persistent back pain. Metastases from prostatic cancer were found in his spine and turned out to be an unusually aggressive variety. On March 21st he said farewell to his department in a brief and moving speech.

He lived free of pain through a beautiful summer with much golfing, gardening and fishing.

Then in September the back pain recurred. The last week of his life he spent in hospital. He had been in pain for a long 
time, but was reluctant to take the drugs that had been prescribed. He said that if he had to die, at least he wanted to do it with his wits about him, not in a narcotic haze. In December 1973 he composed the following letter to be distributed in the department.

\section{(Translated)}

To all the good friends I worked with as head of the Department of Neurosurgery

As you know I have been on sick leave since March. In April I applied for early retirement on grounds of incurable illness, and this was granted by the President of the Republic on November 16th. I was appointed to the Chair of Neurosurgery as well as head of the department 10 years ago, and if we count the interregnum after the retirement of Professor A. Snellman, I was in charge of the department for $12 \frac{1}{2}$ years (Fig. 3).

The department was then, and still is, the smallest within the Helsinki University Central Hospital (HUCH) with regard to the number of beds. We acquired some beds in Ward 8 for neurotraumatology, so within the Töölö Hospital we now have 65 beds; in addition, we had access to some 15 beds for convalescents elsewhere. As a section for neurosurgery was started up in Turku in 1967 with some 20 beds, and a Chair in Neurosurgery with 26 beds was scheduled for Oulu, the future of neurosurgery in Finland looked brighter than ever. But, alas, a new A \& E department swept away our convalescent

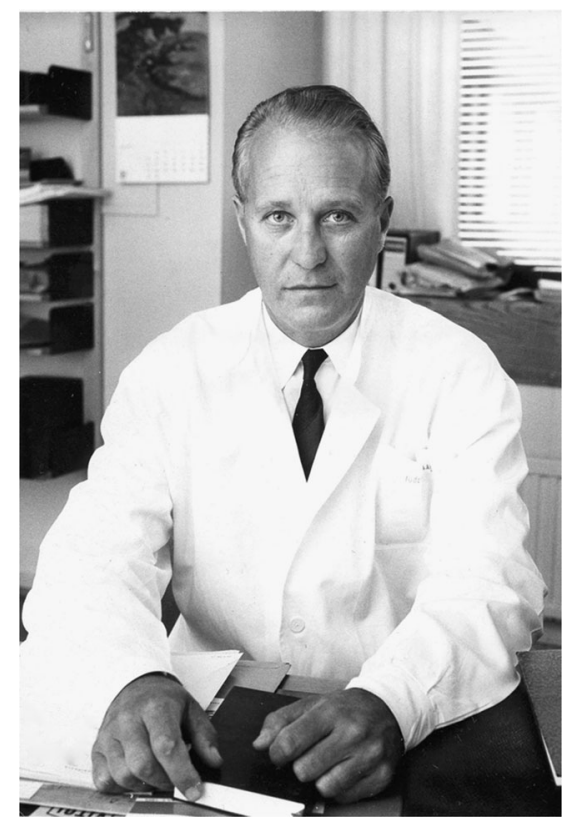

Fig. 3 Gunnar af Björkesten has a serious face for the photographer. (Private collection of Professor Gunnel Adlercreutz, née af Björkesten, copyright: gunnel@adlercreutz.fi) beds, putting more strain on our resources in Töölö, and the newly appointed board of scientific advisors to the government has recommended deferral of the Oulu unit by at least a year. These events show that it will become ever more difficult to raise neurosurgical capacity; I can but hope that my successor will do better than I did. The department can do nothing about the present shortage of nurses. This too has led to a considerable reduction of neurosurgical services this year.

In spite of such difficulties and limitations it has been a great and encouraging experience to head this small, but active and energetic unit. The research activity has been impressive, and in relation to size the department has produced more senior researchers than any other department within the HUCH: six docents over 10 years, and ten doctoral dissertations, three of them on anaesthesiology. Every year the department has published 25-30 scientific papers.

The division of tasks among the senior neurosurgeons has proved to be a good system; almost everyone has had some subspecialty, and with that the task of supervising dissertations. The financing of research has been reasonable: over 10 years we received some 250,000 Finnish marks from Helsinki University, the Sigrid Jusélius Foundation, and the University Pharmacy. At least senior neurosurgeons have also been able to get additional funding from other sources.

Neurosurgical nursing is demanding, often stressful both physically and psychologically. Throughout I have admired, indeed it has been a joy, to see with what dedication, enthusiasm and good cheer the entire staff of our wards and theatre have taken on their tasks (Fig. 4). I wish to remind you that when our so-called "Observation Ward" started up in 1960 it was the first intensivecare unit in Finland. Small and hardworked, it was a pioneer in its time. Cooperation with the sections for anaesthesia, radiology, physiotherapy and the laboratory has been excellent throughout.

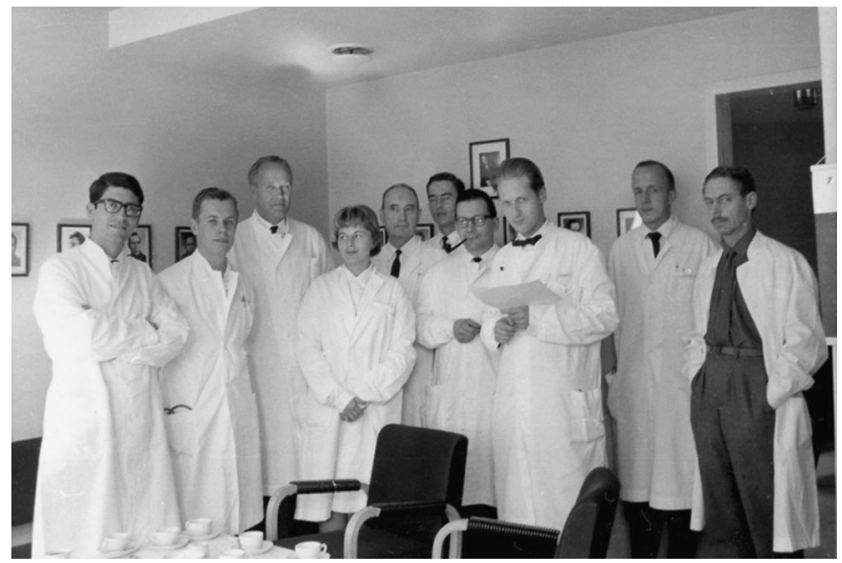

Fig. 4 Gunnar af Björkesten in the coffee room of the neurosurgical operative theatre at Töölö hospital in the mid-1960s. Left to right: unknown, Matti Vapalahti, Gunnar af Björkesten, Irja Marttila, Teuvo Mäkelä, J. Suvanto, Seppo Pakarinen, Henry Troupp, Olli Heiskanen, Yrjö Temmes. (Private collection of Professor Henry Troupp, copyright: heutropp@bastu.net) 
I feel that the contact and cooperation between the different professional groups within the department has usually been close and effective. In particular, the general use of first names between people working closely together has felt good. I believe this to be an instance of true democracy, not that we should start voting about tests, treatment, etc., but it demonstrates that everyone in the department feels equally involved in the smooth and effective work for our patients.

Today, 17 December 1973, the allotted time for application for the Chair of Neurosurgery has expired. It will be a lengthy process before my successor as professor and head is appointed, nor shall I ever know who he is. I thank you all for your skilful and dedicated work in neurosurgery through these many years; and I wish you success and happiness in your work and your private life, and I sincerely hope neurosurgery in Finland will have better conditions in future.

Yours

Gunnar af Björkesten

Neurosurgical capacity in Finland has never been generous: 20 beds in the early 1950s, 85 in the years 1962-72 reduced again in 1974 to some 60 because of a shortage of nursing staff. Gunnar af Björkesten accepted that the scarce resources would be best used by a policy of giving preferred treatment to the patients who might recover well, leaving to their fate patients with such diseases as malignant gliomas, metastatic brain tumours, spontaneous cerebral haemorrhage and cervical spondylosis. In addition to the department in Helsinki, in 1974 there was one neurosurgical unit of some 20 beds in Turku (in the west of Finland), with one neurosurgeon in attendance. The neurosurgical unit in Oulu in the north was to be delayed for over 4 years. The Medical Board (since abolished) kept a tight rein on developments in healthcare, but had recently created a number of attractive nursing posts in primary care. At the same time, the Board of Vocational Training had reduced the intake of student nurses with the foreseeable effect of a shortage of trained nurses, who naturally preferred posts where the work was lighter and kept regular hours. The Helsinki Department of Neurosurgery was hard hit, occasionally so hard that an entire ward had to be closed down.

Acknowledgments The authors are grateful for the invaluable contribution of Professor Gunnel Adlercreutz, née af Björkesten and Carl-Erik af Björkesten.

Conflicts of interests None.

\section{References}

1. Törmä T (1994) Aarno Snellman, the pioneer of modern neurosurgery in Finland and the founder of the Neurosurgical Clinic of Helsinki University Hospital. Hippokrates (Helsinki) 11:84-94

2. Törmä T (1981) Perspectives in international neurosurgery: neurosurgery in Finland. Neurosurgery 9:479-481

3. Törmä T (1963) Development of neurosurgery in Finland. Duodecim 79:196-199

4. Troupp H (1974) Gunnar af Björkesten in Memoriam. Acta Neurochir (Wein) 31:139-142 